\title{
Cultural and Textual (Dis)unity: Poetics of Nothingness in The Waste Land
}

\author{
Petar Penda \\ University of Banja Luka
}

Poets of modernism were by and large preoccupied with the idea of disorder. This preoccupation reflected itself in their style, as well as in general views on post-World War I culture. Fragmented society, detachment from the past and tradition in many aspects of human lives, gradual liberation from social constraints and norms, density of cities and mobility of their inhabitants - all of these factors led to new forms of viewing human culture. The Great Depression and its consequences strengthened the feeling of impossibility of loosening the grip of the past. The economic crisis also brought about a sense of pessimism in most men and women of the time. These were the social conditions that formed new aesthetics which consisted of two opposing stances: Pound's credo "Make It New" on the one hand, and the insistence on keeping traditional values on the other.

In The Waste Land, as well as in several of his essays, T. S. Eliot glorifies the concept of disorder, but eventually tries to make his poem more comprehensible and orderly by providing explanations to his allusions in extensive endnotes. He also insists on filling the fissures of modern difficulties with numerous references to a meaningful past. The Waste Land's ideas of non-being and its sense of a nothingness of life that leads towards disorder are opposed to the implicit idea of establishing order. Likewise, in his essays, Eliot puts emphasis on the idea of imposing aesthetic / ideological order with his vision of an organic cultural unity. This duality of nothingness of life on the one hand, and establishing order and comprehensibility on the other, is reconciled by means of the aesthetic unity of opposites.

The insistence on the aesthetic reconciliation of the above dichotomies, which Eliot sees as possible only in reference to the past, bears ideological traits common to many modernist writers. An 
aesthetic of nothingness realized through a paradoxical poetic of disorderly order leads to what Terry Eagleton terms as the "ideology of cultural disintegration." The aim of the present paper is to scrutinize the interrelation of both Eliot's theoretical poetics and the poetics utilized in The Waste Land regarding the ideological aspects of the aesthetic of disorderly order.

Although revolutionary when it comes to poetic forms, Eliot was rather conservative in relation to cultural changes. This reactionary attitude is seen both in his poetry and his theoretical concepts represented in his essays and longer studies, primarily in The Waste Land and Notes Towards the Definition of Culture. Defining 'culture' in the latter text, Eliot emphasizes the interdependence of the cultures of the group, the individual, class, and the society. He states that the culture of the society is fundamental and exceeds all the others; he further claims that we "find it in the pattern of the society as a whole" (Notes 23; my emphasis). It is obvious from this statement that Eliot sees the social hierarchy as something fixed and unchallenged. The concept of hierarchy realized through unified culture is further reinforced when he writes about its disintegration and the possibility of repairing the "malady." The viewpoint that cultural fragmentation leads to disintegration and that this process relates to the disintegration of a class or between classes speaks in favor of social harmony and hierarchy. Being an advocate of high culture, Eliot is also a promoter of high class since he sees it as the principal bearer of cultural advancement. The questions about the control of, and deliberate influence on, culture speak for the ideological position that culture is "the property of a small section of society" (Notes 33). In addition to this view, Eliot also equates spiritual aspects of art and religion and sees religion as something that gives meaning to life and protects humanity from despair.

Writing on culture, Eliot is highly aware both of its power and of the human attempt to structure and frame it. Although he insists that both certain degrees of unity and diversity are necessary within a society in order to develop its culture, it is order he insists on, which again represents a measure imposed by the class in power. Allowing a regional "characteristic culture" with slight differences in regard to a larger community, he insists on harmonization of the neighboring areas and terms it an "absolute value of culture." Furthermore, Eliot suggests that the reconciliation of the local and communal should be unconscious: "The unity with which I am concerned must be largely 
unconscious, and therefore can perhaps be best approached through a consideration of the useful diversities" (Notes 51-52). Cultural unity is here based on loyalty, which stems from the family and then extends into a local community and finally into a nation. However, such a concept presupposes more or less a firm hierarchy and thus cultural unity is not unconscious but dictated and imposed. It is ambiguous whether with "unconscious" Eliot thinks of unawareness of the conceived concept, or whether it stands in for a natural process. If it is the latter, then it is a contradiction in terms. The idea of the necessity of studying culture also implies that culture is disorderly and that nothingness instead of meaningfulness pervades.

Eliot's concepts of tradition, order, myth, and poetic impersonality also lead to the idea of the organic unity of culture and society on the whole. The acquisition of tradition is represented as absolutely necessary for anyone who wants to take his or her place in the literary canon and change the existing order. The paradox lies in the idea that the artist has to accept the hierarchy and become part of it in order to change it. And this work would be futile by only learning about tradition; it demands its acquisition. To obtain tradition, Eliot says, involves acquisition of "the historical sense":

It cannot be inherited, and if you want it you must obtain it by great labour. It involves, in the first place, the historical sense ...

$$
[\ldots]
$$

$\ldots$ and the historical sense involves a perception, not only of the pastness of the past, but of its presence; the historical sense compels a man to write not merely with his own generation in his bones, but with a feeling that the whole of the literature of the literature of Europe from Homer and within it the whole of the literature of his own country has a simultaneous existence and composes a simultaneous order. (Selected Essays 14)

The idea of "obtaining" or "acquiring" tradition implies that what we acquire becomes an inherent part of us, while "learning" implies mere knowledge of tradition. Eliot suggests that the artist learns about and becomes part of a system if he wants to improve his position in the given hierarchy. Glorification of tradition as the only means of being a writer after one is twenty-five and insisting on becoming a systemic constituent leaves hardly any space for revolutionizing culture. The idea of tradition is certainly not in accordance with the modernist call "Make It New!" The explanation for becoming part of a system and revolutinizing it lies in the historic dialectics where the marginalia 
oftentimes turns into the mainstream until, again, it becomes replaced by another marginalia. Eliot's biography and cultural work illustrate this transformation. A bank clerk, despised émigré, and writer of "nonsensical" lines develops into a commanding literary and cultural figure - a critic and writer who dictates the taste of his time. The marginalia embodied in Eliot's and Pound's work and influence thus becomes the mainstream that greatly influences culture on both sides of the Atlantic.

Tradition in The Waste Land is also insisted on by numerous references and allusions to the works of art of Eliot's predecessors. Copious citations evoke the past and create a counterbalance to the present. A commensurate relation of the two establishes a poetic dynamics of "pastness of the present," that is, the concept that the past is inseparable from the present and represents its indivisible constituent. This idea was developed further in the Four Quartets, but The Waste Land first introduces it. A shift from past to present and vice versa continually transforms our vision of the past and the present, providing new perspectives and suggesting a fluidity and instability of human categories and experiences. The oligarchy is seemingly replaced by a multitude. Seemingly because it is not the chaos of his time that Eliot views with positive attitude. By introducing the concept of the past by alluding to ancient works of art and history, Eliot tries to overcome the chaotic state and establish a balanced unity between the two. Thus the textual disunity which is achieved by Eliot's discursive style serves to create an aesthetic of harmony, which is yet again a way of his ideology acting against the normative. Non-compliance is here represented by the chaoticity of the society which is to be ultimately redeemed and replaced by stability.

Eliot's theory of impersonality, expounded in his essay "Tradition and Individual Talent," is also in line with the idea of cultural unity. Relying on a "continual extinction of personality" (The Sacred 17) and "depersonalization" of his experience, an artist is supposed to achieve a universality of emotion. The writer is just a medium "in which impressions and experiences combine" (The Sacred 20) in order to create an "artistic emotion," which is again supposed to express a general truth and a general symbol. Yet a general truth and a general symbol depend upon a combination of political, ethical, aesthetical, and ideological perspectives, and it is certain that they fluctuate and vary in different cultural contexts and 
milieus. Thus the powerless and the powerful are likely to have dissimilar ideas of a common truth. Depersonalization to a great extent equals de-individualization in the theory of impersonality and can be read as markedly ideological. It is moreover so because Reason is supposed to be superior to emotion; that is, emotions are to be controlled by Reason. An escape from a personal emotion and the tendency to reach universality by means of Reason is by and large striving for an artificial unity. Since emotions are depersonalized, so is Reason. By knowing that the impersonality theory stems from the concept of tradition and that it encompasses a writer's endeavor to obtain it and become part of the canon, we find that Reason is presented as normative. Prescribed norms are essentially ideological and so is the cultural and textual unity achieved by depersonalization of one's emotions.

As the very title of Eliot's essay "Ulysses, Order and Myth" suggests, myth and mythic patterning are seen as organizing structures. Similar to the idea of tradition, the task of the mythical method involves "manipulating parallel[s] between contemporaneity and antiquity" in order to control and give shape and significance "to the immense panorama of futility and anarchy which is contemporary history" (Selected Prose 177). Eliot's discourse advocates the ideology of forced harmony which is to be achieved by "controlling," "ordering," and "giving shape." Paralleling the glorious past with the history of his time, Eliot emphasizes the necessity of restoring the past and conquering the contemporary disorder. The dogma of the normative and structured society prevails and is represented as an absolute necessity if the present chaos is to be overcome.

The mythic in The Waste Land is presented through a number of allusions to fertility rites and vegetation myths derived from Frazer's Golden Bough and Jessie Weston's From Ritual to Romance. As Rebecca Beasley states, although The Waste Land repeatedly enacts a sacrificial drowning, it is death rather than resurrection that is emphasized, and the wasteland is not returned to fertility by the end of the poem." She adds that even the final refrain "'Shantih, shantih, shantih,' translated by Eliot as 'the peace which passeth understanding' is inadequate" as it does not represent a resolution (Theorists of Modernist Poetry 85).

However, these allusions to Frazer's and Weston's books could be given a slightly different reading than the one Beasley offers. By depicting the mythic past and its possibilities for overcoming its 
own difficulties, Eliot simply "speaks" in favor of the past and its hopes for the better times to come. On the other hand, by giving a picture of the present, without the possibility or even an attempt to reach a resolution, he accentuates the downfall and degradation of the present society. This, of course, puts emphasis on cultural and social disunity in general as present day men and women are not able to act communally. How, then, do the final words "Shantih, shantih, shantih" fit the text? One explanation could be that they represent textual disunity which purposely conforms with cultural disunity. Alternatively, these words can stand for both the philosophic understanding and acceptance of the given condition, which again brings social "peace" and cultural / textual unity. In both cases, they represent the textual aestheticization which conceals the ideology of order and cultural unity. As Kenneth Asher put it: "mythology will be far more than just the literary method suggested in the comments on Ulysses. He [Eliot] is intent on ordering not only the literary representation of reality but the reality itself" (T. S. Eliot and Ideology 63).

Allusions to figures such as Frazer and Weston, as well as the employment of motifs drawn from myth, serve to demonstrate the impossibility of separating the past and the present. In ideological terms, some values are to be preserved regardless of the social changes. Stability based on hierarchy and order is insisted upon. This stability is required in every field of human action: education, politics, art, everyday affairs, and culture in general. Eliot's allusions, however, contribute to creating a new poetic form, but as far as ideas are concerned, it is as if he replaced Pound's credo "Make It New" with "Make It Difficult" in order to make art and culture inaccessible to common people. Writing on the metaphysical poets, Eliot states:

\footnotetext{
it appears likely that poets in our civilization, as it exists in present, must be difficult. Our civilization comprehends great variety and complexity, and this variety and complexity, playing upon a refined sensibility, must produce various and complex results. The poet must become more and more comprehensive, more allusive, more indirect, in order to force, to dislocate if necessary, language into its meaning. (Selected Essays 289)
}

The necessity of "forcing" and "dislocating" language in order to give it meaning points to Eliot's idea of creating order by giving words and, in the wider context, culture a certain set of meanings. This process of language violation aims at segregating different social 
groups as the process demands "a refined sensibility," which is a quality of the intellectual elite. And this intellectual elitism is rather related to aristocratic elitism. Culture, in this respect, is solely a matter of intellectual sophistication reserved for the highest social groups, while allusions, as the inevitable mark of refinement, serve to distinguish between the refined and non-refined, that is, between the higher and lower classes. Eliot's use of allusions is not only, as Menand suggests, "aesthetic compensation for the loss of epistemological or metaphysical certainty" (Discovering Modernism 49), but it also advances the ideology of social ordering, a design which promotes hierarchical status quo.

Acutely aware of modern society's rupture and the inevitability of social changes that are about to affect literature, Eliot tries to reconcile the disorderly aspects of social life (which are reflected in his poetry) with his inclination towards the continuity that tradition implies. This reconciliation could be termed Eliot's "poetics of disorderly order" which he achieves by aestheticizing life's disorder and the nothingness it leads to. The interface between the social, personal, and poetic is reflected in his attempt to give meaning to the futility and meaninglessness of life. Eliot here acts on two planes: theoretical, which entails the revision of the canon and introduces several new theoretical concepts, and poetic, which is supported by his theoretical concepts.

Let us first examine what Eliot's views on nothingness and life's disorder are. The often quoted statement that he was a "classicist in literature, a royalist in politics, and anglo-catholic in religion" (For Lancelot Andrews ix) tells us that he appreciated order and tradition above all. The idea that anyone who wants to write after he is twentyfive needs to acquire a sense of tradition emphasizes Eliot's standpoint that tradition should serve the purpose of persevering continuity in literature, just as literature serves to maintain tradition in general. The concept of objective correlative, "a set of objects, a situation, a chain of events which shall be the formula of that particular emotion" (Selected 145) also suggests order as the most appreciated detail in a literary work of art. This point of view, coupled with the idea of new works of art altering the existing order in literary history, designated Eliot both as a challenger of the existing order and the keeper of traditional order on the whole. Establishing order and thus giving meaning to life and art seems of the utmost importance to Eliot. How then do nothingness and disorder fit into his poetics? In what way 
does Eliot reconcile nothingness and disorder on the one hand and the idea of order on the other?

Observing a great number of images and topics that make up the themes and structure of The Waste Land, one cannot help but notice a multitude of contrasting and seemingly incoherent representations, references, and subject matters. The first part of the poem, "The Burial of the Dead," shows a disparity between spring's cruelty and winter's warmth related to European political issues, which is followed by the imagery of the roots and branches that grow out of stony rubbish. The limitation of "son of man's" knowledge is viewed by the man's ability to see "only / A heap of broken images" (CP 38). There ensues a number of literary allusions to the Bible and Tristan and Isolde, a prophecy by Madam Sosostris, and an image of London's Tower Bridge with a procession of a dead crowd. Finally, with a couple of allusions to Webster's White Devil and Baudelaire's Fleurs du Mal, Eliot makes a reference to the myth of Osiris and concludes by threatening and identifying the poetic subject with a "hypocrite lecteur": "You! Hypocrite lecteur!-mon sembable,-mon frère!" ( $C P$ 39). Incoherence points towards disorder.

The same tone and the motif of inconsistency follow the second part, "A Game of Chess." The story of a neurotic woman waiting for her lover shifts to a constantly interrupted dialogue of the two women in a restaurant about their friend Lil, her husband who is supposed to come back from the war, and how she spent her money on an abortion instead of making herself smart and getting teeth. Both upper and lower classes live a meaningless life of despair and hopelessness which is emphasized by purposeful grammatical ambiguity and insistence on the word "nothing":

Nothing again nothing.

'You know nothing? Do you see nothing? Do you remember

'Nothing?' (CP 41)

"The Fire Sermon" includes references to many figures: Elizabethan poets and playwrights, Goldsmith, St. Augustus, Verlaine, etc. The picture of the dead Thames and of foggy London shifts to a passionless and meaningless love-making scene with Tiresias as a witness. An image of urban London shifts to that of the Elizabethan period and then the section ends with Carthage being burnt down. 
Once prosperous, Carthage was destroyed and the implication is that such destiny is awaiting London as well. Barren love making gives no hope for the future. Here, also, the idea of nothingness is emphasized:

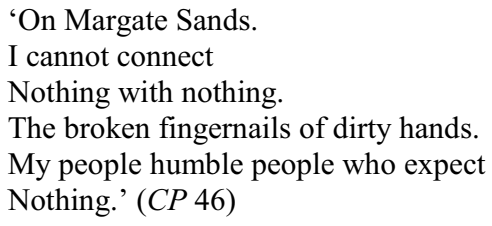

"Death by Water" continues by giving the picture of Phlebas the Phoenician who drowned, and the reminder that he "was once handsome and tall as you" (47), which is again a reminder of human transience based on the contrast of the past and the present. There is no consolation or hope for both life and afterlife, only a sense of loss and the inevitable decay of human flesh.

The final part, "What the Thunder Said," again with the references to many traditional literary works, gives a pessimistic representation of the dead and the dying and the falling towers of both Asian and European capitals. The invitation to give (datta), sympathise (dayadhvam), and control (damyata) is answered as this part finishes with "the peace which passeth understanding" (shantih). Utter pessimism prevails, and it is suggested that both physical and spiritual decay be accepted with peace. However, "the peace" is not spiritually rewarding or consoling, but mere acceptance of the inevitable.

Eliot's allusions to a large number of classical literary works and myths contribute to the organization of The Waste Land. The references contrast the glorious past and its tradition with the disreputable present which again reinforces the feeling of spiritual void and meaninglessness. Pointing out tradition as the prime and ultimate focus of art and life on the whole, Eliot implies life without it is unfulfilling and barren. A sense of tradition and continuity makes life orderly. The idea of orderly life is represented by a series of seemingly random allusions integrated by the idea of present rupture. This concept is further developed by Eliot's extensive endnotes explaining his sources and making more comprehensible his principle plan: "Not only the title, but the plan and a good deal of incidental symbolism of the poem were suggested by Miss Jessie L. Weston's book on the Grail legend: From Ritual to Romance" (CP 50). What he 
modestly (or perhaps preposterously) calls incidental symbolism, also adds up to the poem as a whole.

Other things that make the poem whole are the fragments which are not related to one another on a first reading. Nevertheless, they become related as, conditionally speaking, the storyline develops. Such is the case with Madam Sosostris's prophesy of death by water, which is fulfilled in the section of the same title. The sexual scene between the typist and the clerk gets its full meaning in the pregnancy of another woman, Lil. However, her pregnancy will be terminated and sex thus made equally barren, bringing nothing but the feeling of loneliness and disappointment. Furthermore, Lil's uncertainty related to her husband's return from the war is reflected in the scene with a neurotic woman awaiting her lover. Intertwined in this way, those episodes become more orderly and meaningful.

As the images and events flow into one another, so do the characters. All the characters and their stories are interdependent so that they represent a story of Everyman, the story of the Mankind. In this respect The Waste Land resembles medieval morality plays that also center on human vices that lead to the non-being of humankind and our fall. This is even more so with the introduction of the androgynous character of Tiresias through whose eyes the whole action is observed. The sense of unity fills the fissures of non-being embodied in separate incidents and individual characters. With Tiresias, a multitude is reflected in oneness, while fragments of human consciousness still make a single consciousness of nothingness. As North notes, "the mixtures of styles, languages, and genres in The Waste Land signify a lost linguistic unity, but only by dramatizing its loss" ("Eliot, Lucacs, and the Politics" 178). In this respect, this poem could be considered a lamentation for the loss of general unity.

The insistence on the City as the venue for most of the incidents also contributes to a sense of wholeness in the text. Although Eliot names different geographical sites, London streets and the Thames are the main focus of the poem. This almost Aristotelian unity of place ultimately contributes to the establishing of order. Moreover, the political enmities and personal tragedies caused by the atrocities of World War I throughout Europe are reflected in the chaotic lives of the London inhabitants. They are passionless and dysfunctional due to the death and suffering that encircles them. Future prospects are prophesied to be gloomy and to lead to fatality. The post-World War I society in London, as well as elsewhere, shares the sense of an 
ominous present and an unfulfilling future. Futility and pointlessness permeate every aspect of human life as well as many images that symbolize those feelings. Whether it is the image of a crowd of dead people over London Bridge ["A crowed flowed over London Bridge, so many / I had not thought death had undone so many" (CP 39)], or the image of the Thames that does not testify that the city is alive ["The river bears no empty bottles, sandwich papers, / Silk handkerchiefs, cardboard boxes, cigarette ends / Or other testimony of summer nights. The nymphs are departed" (42)], or the thunder's lament ["Over endless plains" (48)] all evoke the sentiment of loss and decay. It is these very emotions that give an overwhelming tone of hollowness to the poem.

Cultural and social disintegration in general can be overcome by an ideology of cultural knowledge, as Terry Eagleton suggests:

What the poem signifies, indeed, is not "the decay of Europe" or fertility enabled by such arcane or panoramic motifs. . . . Cultures collapse, but Culture survives, and its form is The Waste Land: this is the ideological gesture of the text, inscribed in the scandalous fact of its very existence. (Criticism 149)

By employing the term cultural knowledge, Eagleton refers to knowledge represented by numerous allusions and references to the ancient works of art and tradition. This knowledge is often related to London and its magnificent past. In so doing, Eliot uses the City as an objective correlative not only to convey the sense of futility and despair of post-war London and society in general, but also, by aestheticizing London, he presents an ideology that suggests the necessity of cultural and social order.

These images, which are desolate and empty, populated with the ghosts of the past, create the cityscape poetics which gives unity to the cultural disintegration. These poetics, which primarily rely on the aesthetisization of the city, reconcile cultural, textual, and ideaistic oppositions and serve to propagate an ideology of organic unity of culture; that is, the unity which is in favor of the domineering class.

Even the structure of The Waste Land, with its discursive style and its seeming incoherence, gives the impression of a contradiction to Eliot's concept of cultural unity. This novelty of introducing a multilayered consciousness, and a number of poetic subjects, makes the poem structurally rather disjointed and for many readers renders it 
unintelligible. Different parts of the poem, even sections within one part, are difficult to relate to each other and fail to make much sense even to many knowledgeable readers accustomed to such a way of writing. However, as Lawrence Rainey suggests, "in the new climate of taste, one that Eliot himself did much to usher in, there was no longer a tension between the text of The Waste Land and the claims to coherence" (Revisiting The Waste Land 117). Making the "incoherent" and fragmentary an acceptable poetic idiom, Eliot succeeded in creating a new aesthetic form. Such a "disjunctive form" with "the absence of transition" (Approaches to Teaching 140), at first glance, shows a disruptive and disunified cultural reality; however, when scrutinized more carefully, the poem is clearly loaded with the ideology of its contrary states: order and unity that propagate no changes. And this unchanging condition is in favor of the royalist and Anglo-Catholic politics that Eliot stood for. This is a locus where his poetry, poetics, and social engagement meet and overlap to the greatest possible extent.

\section{Works Cited}

Asher, Kenneth. T. S. Eliot and Ideology. Cambridge: Cambridge UP, 1998.

Beasley, Rebecca. Theorists of Modernist Poetry: T. S. Eliot, T. E. Hulme, Ezra Pound. London: Routledge, 2007.

Eagleton, Terry. Criticism and Ideology: A Study in Marxist Literary Theory. London: Verso, 2006.

Eliot, T. S. For Lancelot Andrews. London: Faber and Gwyer, 1928.

- Notes Towards the Definition of Culture. London: Faber and Faber,1962.

The Sacred Wood: Essays on Poetry and Criticism. New York: Bartleby, 2000.

- Selected Essays. London: Faber \& Faber, 1951.

Selected Prose. London: Faber and Faber, 1975.

Hargrove, Nancy, D. "Teaching The Waste Land in the Context of the 1920s." Approaches to Teaching Eliot's Poetry and Plays. ed. Jewel Spears Brooker. New York: MLA. 1988. (139-143)

Menand, Louis. Discovering Modernism: T. S. Eliot and His Context. Oxford: Oxford UP, 2007. 
North, Michael. "Eliot, Lukacs, and the Politics of Modernism." in T.S. Eliot: Modernist in History. ed. Ronald Bush. Cambridge: Cambridge UP, 1991.

Rainey, Lawrence. Revisiting The Waste Land. London: Yale UP, 2005. 